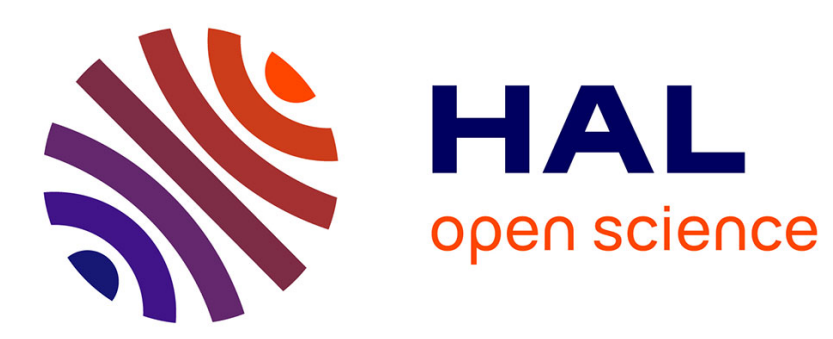

\title{
Tilapia prolactin: Molecular cloning of two cDNAs and expression in Escherichia coli
}

\author{
F. Rentier-Delrue, D. Swennen, Patrick Prunet, M. Lion, J.A. Martial
}

\section{To cite this version:}

F. Rentier-Delrue, D. Swennen, Patrick Prunet, M. Lion, J.A. Martial. Tilapia prolactin: Molecular cloning of two cDNAs and expression in Escherichia coli. DNA Barcodes, 1989, 8 (4), pp.261-270. 10.1089/dna.1.1989.8.261. hal-02728004

\section{HAL Id: hal-02728004 \\ https://hal.inrae.fr/hal-02728004}

Submitted on 2 Jun 2020

HAL is a multi-disciplinary open access archive for the deposit and dissemination of scientific research documents, whether they are published or not. The documents may come from teaching and research institutions in France or abroad, or from public or private research centers.
L'archive ouverte pluridisciplinaire HAL, est destinée au dépôt et à la diffusion de documents scientifiques de niveau recherche, publiés ou non, émanant des établissements d'enseignement et de recherche français ou étrangers, des laboratoires publics ou privés. 


\title{
Tilapia Prolactin: Molecular Cloning of Two cDNAs and Expression in Escherichia coli
}

\author{
F. RENTIER-DELRUE, D. SWENNEN, P. PRUNET,* M. LION, \\ and J.A. MARTIAL
}

\begin{abstract}
We have isolated cDNA clones encoding tilapia prolactin (tiPRL) from a cDNA library prepared from tilapia (Oreochromis niloticus) anterior pituitary glands. A trout PRL cDNA fragment was used as hybridization probe to select the recombinant plasmids carrying the tiPRL coding sequence. Two types of PRL cDNA were isolated and their complete nucleotide sequence determined. The larger cDNA (tiPRL-I) codes for a polypeptide of 212 amino acids, including a putative signal sequence of 24 amino acids, and contains a $3^{\prime}$ untranslated region of $787 \mathrm{bp}$. The second prolactin cDNA (tiPRL-II) encodes a polypeptide of 200 amino acids, including a presumptive signal peptide of 23 amino acids, and contains a noncoding region of 512 bp. tiPRL-I and tiPRL-II cDNA sequences are $81 \%$ similar, whereas the encoded proteins share $69 \%$ amino acid identity at optimal alignment. Mature tiPRL-I was efficiently expressed in Escherichia coli carrying a plasmid in which the tiPRL-I CDNA was under the control of the $\$ 10$ promoter of $T 7$ bacteriophage. The new recombinant protein representing about $45 \%$ of the total cellular proteins was found in inclusion bodies and cross-reacted with salmon PRL antiserum.
\end{abstract}

\section{INTRODUCTION}

A S IN OTHER VERTEBRATES, prolactin (PRL) in fish has a pleiotropic spectrum of biological activities that are involved in a variety of physiological mechanisms such as osmoregulation, reproduction, metabolism, behavior, and mucus production. Most studies devoted to this hormone in fish deal with its osmoregulatory activity. PRL's role in supporting freshwater adaptation has thus become increasingly established (for review, see Clarke and Bern, 1980; Loretz and Bern, 1982; Hirano, 1986).

Tilapia is generally considered as a euryhaline fish capable of adapting to high saltwater salinity. Recent development of tilapia aquaculture in brackish water or in seawater has emphasized salt tolerance problems and has raised new interest in the physiology of osmoregulation in this species (Prunet and Bornancin, 1989). PRL is certainly among the most important hormones involved in the control of hydromineral balance in tilapia (Dharmamba, 1970; Dharmamba and Maetz, 1972, 1976; Clarke, 1973; Foskett et al., 1982).

Recently, two tilapia PRLs have been isolated from culture medium of pituitaries from the tilapia species Oreochromis mossambicus (Specker et al., 1985a; Yamagushi et $a l .$, 1988). Biochemical analyses indicated that these two forms are distinct proteins of different sizes, but studies on the osmoregulatory activities of both PRLs did not indicate any clear differences (Specker et al., 1985a; Young et al., 1988).

A more complete characterization of biological activities of both PRLs in tilapia would be of interest. However, this would require large amounts of pure hormone. To achieve such hormonal production and to gain more insight into gene regulation requirements underlying biological activities of both PRLs, we constructed a tilapia (Oreochromis niloticus) pituitary cDNA library. In this report, we describe the molecular cloning and characterization of two PRL CDNAs differing in size, and the expression of the larger of these cDNAs in Escherichia coli.

\section{MATERIALS AND METHODS}

Plasmid pUC13 and cDNA synthesis kit were purchased from Amersham Laboratories. The sequencing kit was from the United States Biochemical Corporation. Enzymes were purchased from Amersham Laboratories and Boehr- 
inger Mannheim. The synthetic oligonucleotides were provided by Eurogentec S.A. (Liege, Belgium). They were purified by electrophoresis on $16 \%$ polyacrylamide gels containing $7 M$ urea (Narang et al., 1979).

\section{cDNA library construction}

Fresh pituitaries froom tilapia ( $O$. niloticus) raised in freshwater were collected at the CERER (Warm Water Pisciculture Center, Tihange, Belgium). To enrich the preparation in PRL mRNA-producing cells, the anterior part of the pituitary gland was isolated. Total RNA was purified by the guanidium isothiocyanate procedure (Ulrich et al., 1977; Chirgwin et al., 1979) and mRNA was purified by chromatography on oligo(dT)-cellulose. Oligo(dT)-primed cDNA was synthesized according the Gubler and Hoffman (1983) procedure. The doublestranded cDNA was size-fractionated by chromatography on Sepharose 4B (Pharmacia), and blunt-ended molecules larger than 700 nucleotides were inserted into the pUC13 plasmid (Viera and Messing, 1982), previously cut by Sma. I, and dephosphorylated. The ligated product was introduced into $E$, coli RR1 $\Delta$ M15 (lacZ, M15, F', lacIq, ZM15, proA) (ATCC collection), according to Mandel and Higa (1970), and grown on Luria broth (L broth) plates containing $100 \mu \mathrm{g} / \mathrm{ml}$ of ampicillin, $0.5 \mathrm{mM}$ isopropyl- $\beta$-D-thiogalactoside (IPTG), and 0.01\% 5-bromo-4-chloro-3-indolyl$\beta$-D-galactopyranoside (X-gal).

\section{cDNA screening}

White colonies containing plasmid with cDNA insert were transferred to nitrocellulose filters and grown overnight. They were lysed, neutralized, and fixed (Grunstein and Hogness, 1975). Prehybridization was carried out in $6 \times \operatorname{SSC}(1 \times$ SSC: $0.15 M \mathrm{MaCl}, 0.015 M$ sodium citrate $)$, $1 \times$ Denhardt's solution ( $0.02 \%$ each of Ficoll, polyvinylpyrrolidone, and bovine serum albumin), and denatured salmon sperm DNA $(100 \mu \mathrm{g} / \mathrm{ml})$. Hybridization was performed overnight at $45^{\circ} \mathrm{C}$, in the same buffer, with ${ }^{32} \mathrm{P}$-labeled probe. Filters were washed in $6 \times \mathrm{SSC} / 1 \times$ Denhardt for $30 \mathrm{~min}$ at room temperature, then washed for $30 \mathrm{~min}$ at temperatures up to $54^{\circ} \mathrm{C}$.

\section{DNA sequencing}

DNA sequence analysis was carried out by the dideoxynucleotide chain-termination method according to Sanger et al. (1977) after cloning of the entire insert in the bacteriophage M13 (mp18 and mp19 vectors) (Yanish-Perron et $a l .$, 1985). Use was made of synthetic oligonucleotide primers in the sequencing strategy.

\section{Construction of tilapia PRL-I expression vector}

Vector pAR3040 (Rosenberg et al., 1987) is a derivative of pBR322 that contains the $\Phi 10$ promoter and the natural T $\Phi$ terminator for T7 RNA polymerase. This plasmid was modified in our laboratory to facilitate cloning by (i) re-

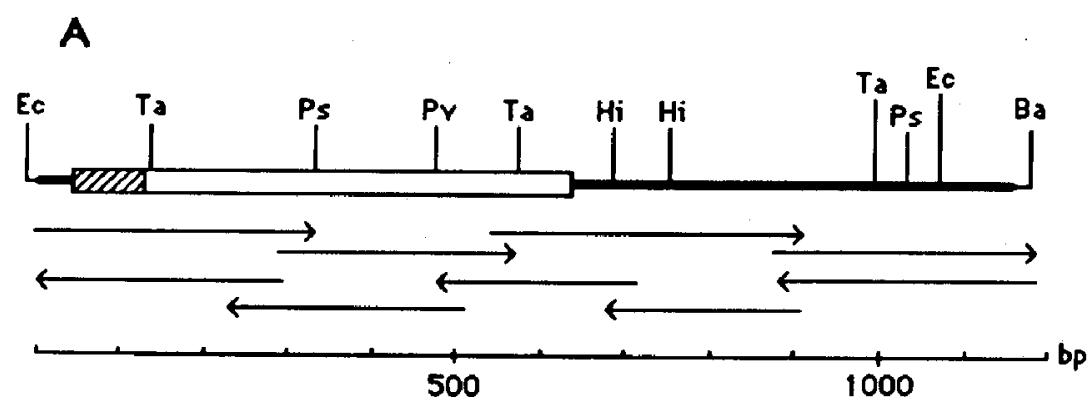

B

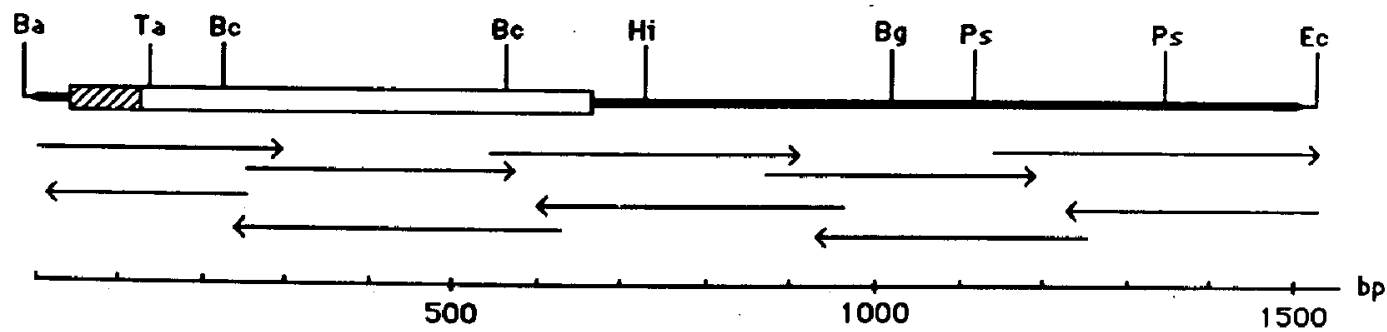

FIG. 1. Partial restriction map and sequencing strategy of tiPRL-I (A) and tiPRL-II (B) inserts. From left to right, the diagram shows: the $5^{\prime}$ untranslated region (thick line), the region coding for the peptide signal (hatched box), the mature tiPRL (open box), and the $3^{\prime}$ untranslated region including the poly(A) tail (thick line). Thin line represents the region of the pUC13 plasmid multiple cloning sites. Restriction enzyme cleavage sites are indicated as follows: $\mathrm{Ba}, \mathrm{Bam} \mathrm{HI} ; \mathrm{Bc}, \mathrm{Bcl}$ I; Bg, Bgl II; Ec, Eco RI; Hi, Hind III; Ps, Pst I; Pv, Pvu II; Ta, Taq I. Arrows indicate direction and extent of sequencing. 
$-26$

$-20$

$-10$

het Ala Gln Arg Arg Trr Ser Giy Mr Asn Leu Pre net Ir Val Leu Crs Val Val

tiphL-1

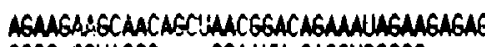

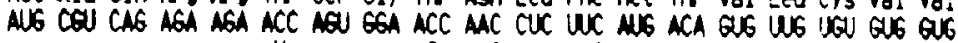

tiPRL-II CCCC-GQUAACCG----CGAMUL-GAGCUCECCC

II

10

Ser Lys

20

Ala het Cys Aro Ala Val Pro lle Asn Glu Leu Phe Glu Aro Ala Ser Gln His Ser Aso Lys Leu His Ser Leu Ser Tr Mr Leu Tr Glo Glu

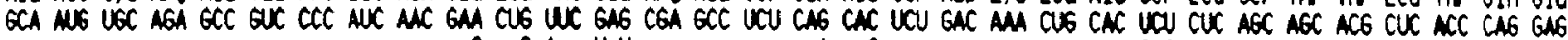

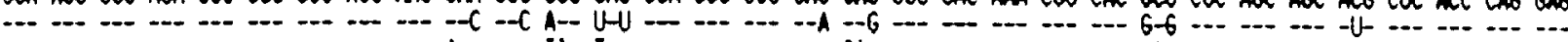
30 Aso Ile $\operatorname{Tr} 60$ Gln 50 Alo het

Leu Aso Ser His the Pro Pro Ile Gly arg Val Ile het Pro Arg Pro Ala het Cys His Trr Ser Ser Leu gin itr Pro Ile Aso Lys Aso Gln

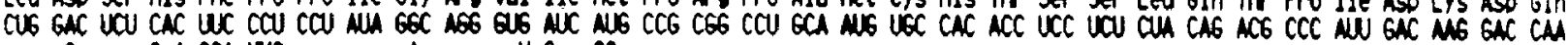
C. GGly Glu Alo the Aso geu Ala ............... Alo Leu Gin Val Ser 6lu Ser Asp Leu net Ser Leu Ala Aro Ser Leu Leu Gin Ala Iro Ser Asp Pro Leu Val Val Leu Ser Ser Ser Alo Ser Glu

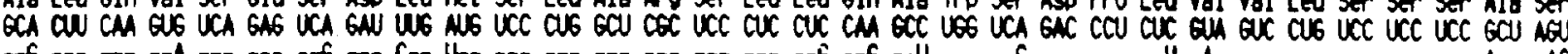

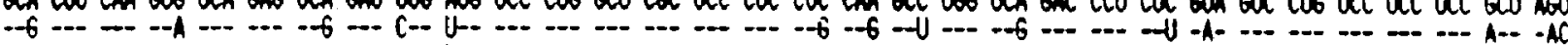
Leu

Glu 120 Tr Asn

Trr Leu Pro His Pro Alo GIn Ser Tre Ile Phe Asn Lys Ile Gln Glu het Gln Gln Tyr Ser Lys Ser Leu Lys Aso Gly Leu AsD Val Leu Ser

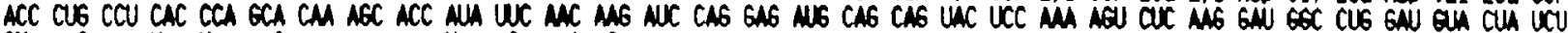

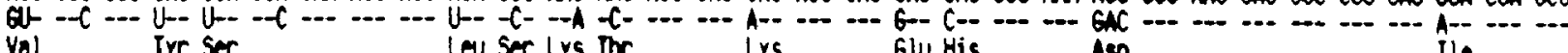

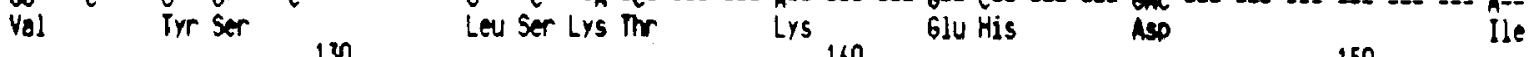

1300160

Ser Lys Met Gly Ser Pro Ala GIn Alo Ile Thr Ser Leu Pro Trr fro Gly Gly Thr Asn Leu Gly His Aso Lys Ile Thr Lys Leu Ile Asn Pre

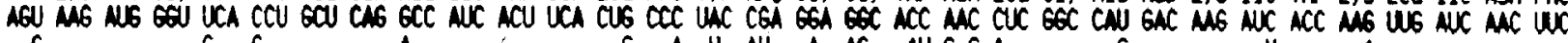

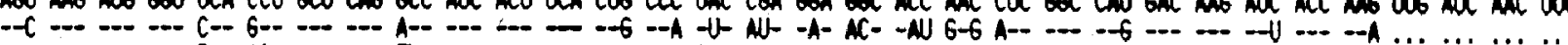

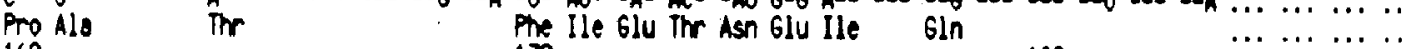
160

Asn Phe Leu Leu Ser Cys Leu Arg Arg Aso Ser His Lys Ile Aso Ser Phe Leu Lys Val Leu Arg Cys Arg Alo Ala Lys het Gln Pro Glu het

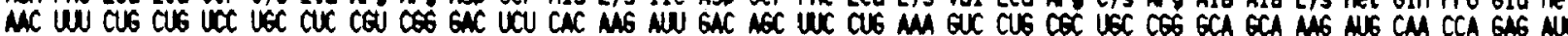

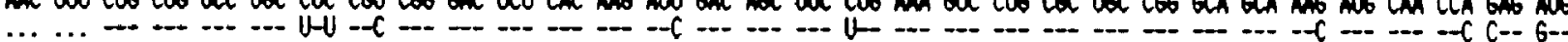
igis $\cdots$ the Asn Gl Vol Crs 00

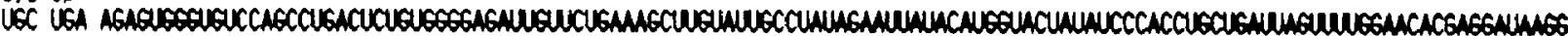

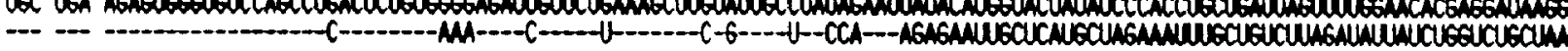

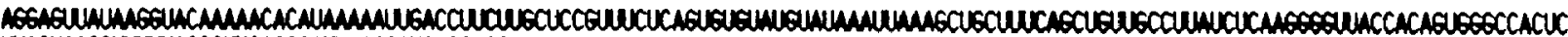

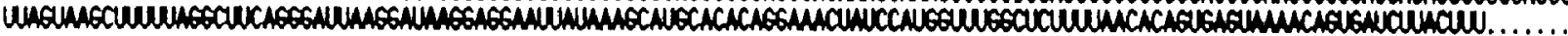

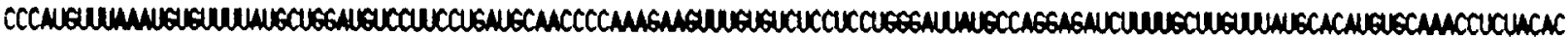

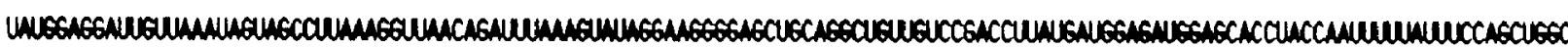

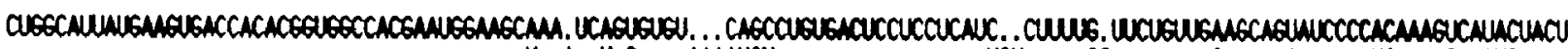

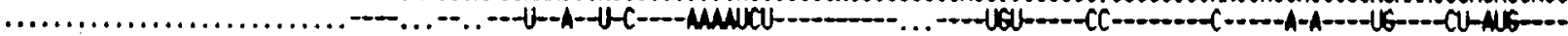

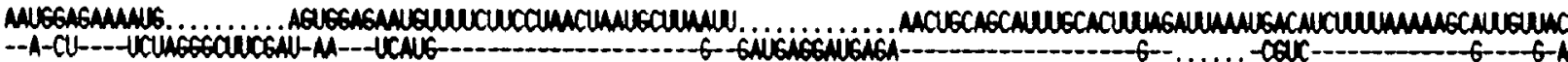

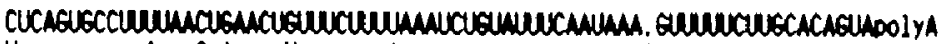

(-

FIG. 2. Complete nucleotide and deduced amino acid sequence of ptiPRL-I and ptiPRL-II inserts. Mature proteins start at amino acid 1. Amino acids with negative numbers represent the signal peptide. For tiPRL-II, only nonhomologous nucleotides and amino acids are given. In the coding regions as well as in the $3^{\prime}$ untranslated regions, gaps have been introduced to maximize homology and are represented by dots.

moving the $P v u$ II- $B g l$ II (thus the $B g l$ II site) fragment and the Eco RI-Eco RV fragments and (ii) replacing the $A v a$ II-Ava II 222-bp fragment of the $\beta$-lactamase gene containing the Pst I site by the same fragment of pUC13 plasmid devoid of this restriction site. This plasmid was called pARAE (C. Gohimont and C. L'hoir, from our laboratory, unpublished results).

\section{Expression of tilapia PRL-I}

Procedure for expressing tiPRL-I was essentially as has been described (Studier and Moffatt, 1986). E. coli strain
BL21 (DE3), a $\lambda$ lysogen of BL21 $\left(\mathrm{r}_{\mathrm{B}}{ }^{-} \mathrm{m}_{\mathrm{B}}{ }^{-}\right.$rifs) in which the prophage carries a copy of the gene for T7 RNA poly. merase under the control of the lac UV5 promoter, was grown from inoculum, overnight, in $5 \mathrm{ml}$ of Luria broth, in the presence of $100 \mu \mathrm{g} / \mathrm{ml}$ of ampicillin. Of this culture, $0.4 \mathrm{ml}$ was used to inoculate $10 \mathrm{ml}$ of the same medium with ampicillin. Synthesis of T7 RNA polymerase was induced by adding $0.4 \mathrm{mM}$ IPTG when the culture reached $\mathrm{OD}_{600}=0.8$. Three hours later, cells were collected, dissolved in Laemmli sample buffer (1970), and analyzed by $\mathrm{NaDodSO}_{4}$ polyacrylamide gel electrophoresis with Coomassie blue staining. 


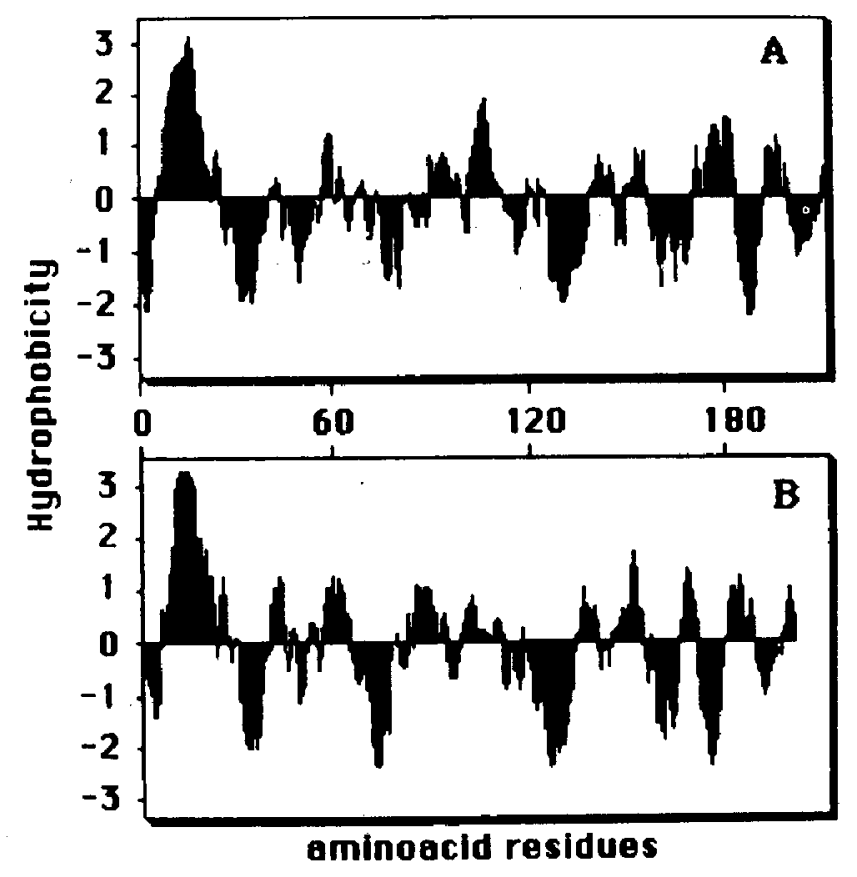

FIG. 3. Hydropathy profile of tilapia PRL-I (A) and PRL-II (B). Hydropathy score for each residue was obtained by averaging the hydropathy indices of 7 amino acids at a time.

\section{RESULTS}

\section{Isolation of two prolactin cDNA clones}

Poly(A) ${ }^{+}$RNA purified from tilapia pituitaries was used as a template for DNA synthesis. Approximately 4,200 recombinant clones were obtained. These clones were hybridized with a ${ }^{32}$ P-labeled 700-bp Eco RI fragment of trout prolactin (Mercier et al., 1989) corresponding to the coding region of the molecule. The washing temperature was raised up to $54^{\circ} \mathrm{C}$. At this temperature, 156 clones hybridized selectively. Among these, 22 full-length clones were analyzed by restriction mapping. They could be divided into two groups based on the restriction map of the inserted CDNA (Fig. 1, A and B). ptiPRL-I contained one $B g l$ II, one Hind III, and one Taq I site as well as two $B c l$ I and $P$ st I sites. Its full length was about 1,600 bp. ptiPRLII contained single Eco RI and Pvu II sites, two Pst I and two Hind III sites, and three Taq I sites. Its full length was about $1,300 \mathrm{bp}$. Out of 22 recombinant plasmids, 16 had the type I pattern and 6 had the type II pattern.

\section{Characterization of tiPRL-I and tiPRL-II}

To confirm that tiPRL-I and tiPRL-II represent tiPRL clones, the nucleotide sequences were determined. Figure
1, A and B, depict the overall structure and sequencing strategy of both prolactin cDNAs, and the complete nucleotide sequences are shown in Fig. 2. The tiPRL-I insert contains a large open reading frame of 636 nucleotides. The $3^{\prime}$ untranslated region is $\mathbf{7 8 7}$ bp long and contains the hexanucleotide AATAAA which precedes the polyadenylation tail of many eukaryotic mRNAs. The encoded polypeptide has 212 amino acids and a calculated molecular weight of 23,534 daltons. The amino-terminal end of the molecule includes a large number of hydrophobic amino acid residues, consistent with the putative role of this segment as a signal peptide that is cleaved off in the secretion process. The mature protein sequence starts at valine residue number 1. This interpretation is based on the known amino acid sequence (Specker et al., 1985a; Yamagushi et al., 1988). The mature protein is thus 188 amino acids long and has a molecular weight of 20,891 daltons.

The tiPRL-II sequence includes a 38-bp 5' noncoding sequence, an open reading frame of $600 \mathrm{bp}$, and a $3^{\prime}$ untranslated region of $512 \mathrm{bp}$ which also contains a polyadenylation signal. The coding region of tiPRL-II encodes a polypeptide of 200 amino acids and a mature protein of 177 amino acids. The molecular weights of the pre- and mature proteins are 22,129 daltons and 19,591 daltons, respectively. The first 23 amino acids constitute the signal peptide.

\section{Comparison of tiPRL-I and tiPRL-II CDNA}

The nucleotide sequence of tiPRL-I cDNA is much longer than that of tiPRL-II cDNA, due to a longer coding region (36 additional nucleotides) and a longer $3^{\prime}$ untranslated region (270 additional nucleotides) (Fig. 2). Codon usage is uneven for both proteins with a preference for guanosine and cytosine in the third position (data not shown). Comparison of tilapia prolactins deduced from the nucleotide sequence reveals that tiPRL-II preprotein is 12 amino acids shorter than tiPRL-I. Furthermore, 50 amino acid substitutions are located at random. In the signal peptide, 1 amino acid is missing in tiPRL-II and 4 amino acids are substituted. The hydrophobicity profiles (Kyte and Doolittle, 1982) of the proteins encoded by tiPRL-I and tiPRL-II cDNA are shown in Fig. 3. For both proteins, a strongly hydrophobic region is found at the amino terminus which corresponds to the signal peptide of the molecule.

\section{Expression of tiPRL-I in E. coli}

Figure 4 shows the construction of the expression vector based on the T7 RNA polymerase (Studier and Moffatt, 1986) for the production of an unfused protein. The pARAE vector, a derivative of pAR3040, was digested by Nde I and Bam HI. Cutting the ptiPRL-I DNA with Taq I and $B g l$ II released a 877-bp fragment containing the complete region coding for the tiPRL-I mature protein, except for its first 20 nucleotides. These nucleotides were synthe- 


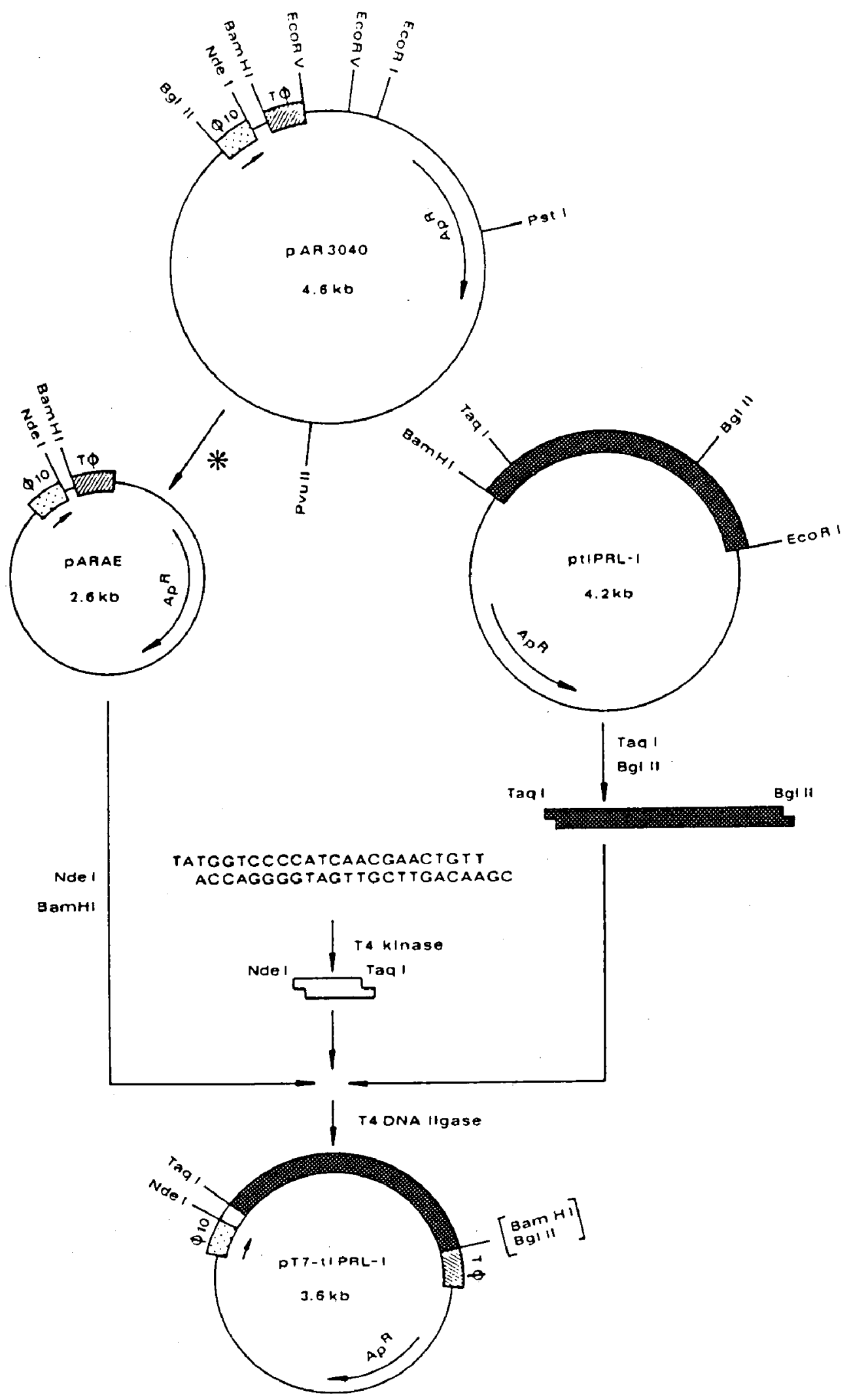

FIG. 4. Schematic representation of the construction of plasmid pT7tiPRL-I. Plasmid pAR3040 was modified as described in the Materials and Methods section $\left({ }^{*}\right)$ and called pARAE. Plasmid pT7tiPRL-I was constructed from pARAE and ptiPRL-I using synthetic oligonucleotides as described in the text. Stippled box and hatched box represent the $\Phi 10$ promoter and T $\Phi$ terminator for T7 RNA polymerase, respectively. Arrow indicates orientation of the $\Phi 10$ promoter. Heavily hatched box in ptiPRL-I represents the entire tilapia PRL-I cDNA. ApR, Gene coding for the ampicillin resistance. 

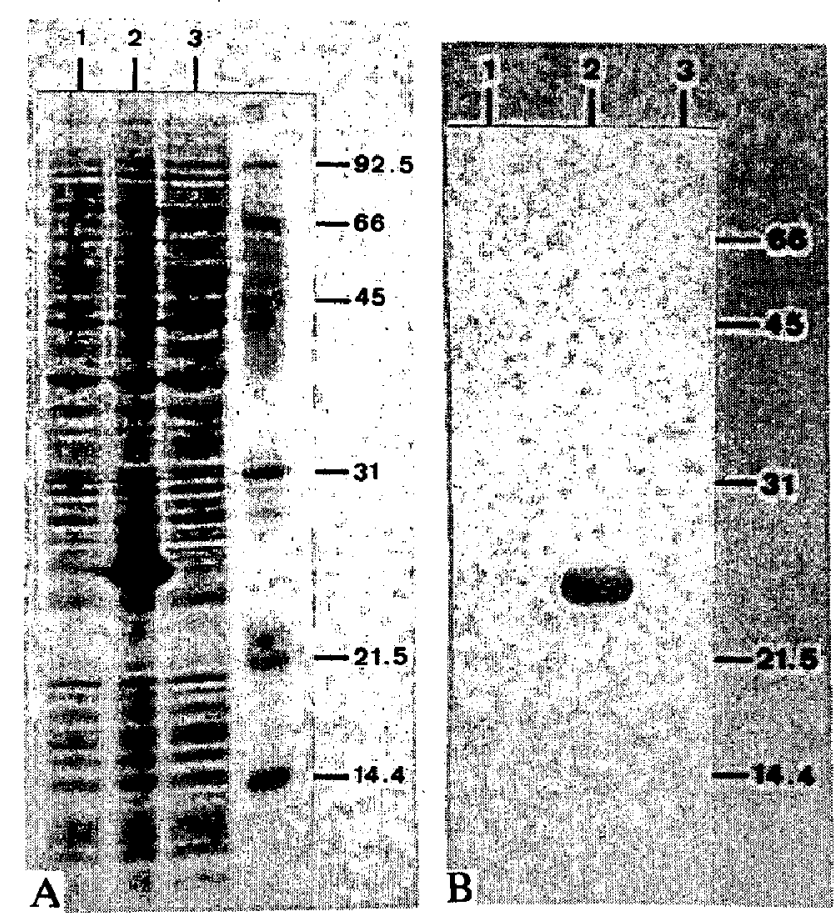

FIG. 5. Analysis of tiPRL-I synthesis by $\mathrm{NaDodSO}_{4}$ polyacrylamide gel electrophoresis. $E$. coli $\mathrm{BL} 21(\mathrm{DE} 3)$ harboring plasmid pT7tiPRL-I was grown at $37^{\circ} \mathrm{C}$ in L broth containing $100 \mu \mathrm{g} / \mathrm{ml}$ ampicillin. At $\mathrm{OD}_{600}=0.8$, synthesis was induced or not with IPTG and culture was grown for $3 \mathrm{hr}$ at $37^{\circ} \mathrm{C}$. Total cell lysate was prepared by centrifuging $1 \mathrm{ml}$ of cells. The pellet was dissolved in $100 \mu \mathrm{l}$ of Laemmli sample buffer and $10 \mu \mathrm{l}$ were heated at $90^{\circ} \mathrm{C}$ for $5 \mathrm{~min}$ and loaded onto a $12.5 \%$ polyacrylamide gel. $\mathrm{A}$. Total cellular proteins of uninduced (lane 1) and induced (lane 2) cells. Lane 3, Total cellular proteins of BL21(DE3) containing the pARAE plasmid without insert. B. Western blot analysis of tiPRL-I. Total proteins were transferred to nitrocellulose (Towbin, 1979) and tiPRL was detected using a salmon PRL antiserum. The immune complexes were revealed by peroxidase-conjugated antibodies.

sized chemically with Nde I and Taq I protruding ends to ensure the correct cloning and orientation behind the $\mathrm{T} 7$ promoter in plasmid pARAE. The ligation products were cloned in $E$. coli strain HB101. The correct recombinant plasmid was identified by standard techniques and called pT7tiPRL-I. To direct the expression in vivo, it was transferred into $E$. coli strain BL21 (DE3).

Expression of tiPRL-I was directed by T7 RNA polymerase. In the presence of IPTG, T7 RNA polymerase is switched on, which allows the expression of genes under the control of the $\mathrm{T} 7$ promoter. Total extracts from induced and noninduced cells were analyzed by $\mathrm{NaDodSO}_{4}$ polyacrylamide gel. In the presence of IPTG, a new protein of about $24 \mathrm{kD}$ appeared, which was absent from extracts of bacteria containing the vector plasmid only (Fig. 5A). The amount of tiPRL was estimated to represent $45 \%$ of the total cellular proteins. In addition, inclusion bodies were observed in bacterial cells carrying the recombinant expression vector. These particles were easily purified by sonication and centrifugation. To confirm the identity of the tiPRL in the induced pT7tiPRL-harboring BL21(DE3) cells, a Western blot analysis was performed on proteins extracted from both induced and noninduced cells, using a salmon PRL antiserum. The results showed that the extra protein whose expression is induced upon addition of IPTG, cross-reacts with the salmon antiserum and should correspond to the tiPRL-I (Fig. 5B).

\section{DISCUSSION}

We have identified two PRL cDNAs in a tilapia ( $O$. niloticus) pituitary cDNA library. Identification was done by hybridization under low stringency with a trout PRL cDNA probe. Compared at a preprotein level, these two tilapia PRLs share 151 out of 212 amino acids. The mature proteins have 132 out of 188 amino acids in common. The larger protein, tiPRL-I, is 11 amino acids longer than the smaller one, tiPRL-II.

A "large" (tPRL ${ }_{188}$ ) and a "small" (tPRL ${ }_{177}$ ) tilapia PRL have already been purified from cultured pituitaries of tilapia $O$. mossambicus, and their complete amino acid sequence determined (Yamagushi et al., 1988). Our PRLs have the same amino acid content as the ones sequenced by these authors with the exception of two amino acid substitutions: $\mathrm{Phe}_{7}$ and $\mathrm{Thr}_{100}$ in $O$. niloticus PRL-I are replaced by $\mathrm{Leu}_{7}$ and $\mathrm{Ser}_{100}$ in the corresponding PRL of $O$. mossambicus. These minor changes are probably species specific.

Ninety-one nucleotide substitutions and 36 deletions distinguish the coding region of tiPRL-I and II cDNAs. This corresponds to $81 \%$ similarity. However, the two proteins share only $69 \%$ amino acid identity at optimal alignment. The discrepancy in the degree of similarity between the nucleotide and protein sequences is a consequence of the high number of nucleotide mutations that cause amino acid replacements. Indeed, only 21 substitutions are located in the third or "wobble" position of their respective codons. It should be noted that, when correctly aligned, two regions of the $3^{\prime}$ noncoding sequences are highly conserved (Fig. 2): the first, close to the stop codon, is $64 \mathrm{bp}$. long and $81 \%$ similar. The second, 292 bp long and located near the poly(A) tail, is $66 \%$ similar. The rest of the $3^{\prime}$ noncoding sequences is completely dissimilar.

A comparison of the nucleotide and the polypeptide sequences clearly shows that the two forms of PRL are products of distinct genes. Two forms of PRL have also been described in salmon (Oncorhynchus keta) (Yasuda et al., 1986). However, in the latter case, both PRLs are highly similar with only 4 amino acid replacements. In trout and salmon, the majority of pituitary hormones are always isolated in pairs with little variation in the amino acid content (Kawauchi, 1983). These genetic variant forms are explained by the tetraploid origin of the Salmonidae family (Ohno et al., 1968). However, it appears that, except for a few cases of gene duplications by tetraploidization among certain so-called "primitive" teleosts such as Salmonidae and Cyprinidae, gene duplication of most teleost fish oc- 


Human
Bovine
Ovine
Porcine
Rat
Mouse
Whale
Carp
Salmon
Trout
Tilapia-I
Tilapia-II

Human

Bovine

Ovine

Porcine

Rat

Mouse

Whale

Carp

Salmon

Trout

Tilapia-I

Tilapia-II

Human
Bovine
Ovine
Porcine
Rat
Mouse
Whale
Carp
Salmon
Trout
Tilapia-I
Tilapia-II

Human

Bovine

Ovine

Porcine

Rat

Mouse

Whale

Carp

Salmon

Trout

Tilapia-I

Tilapia-II

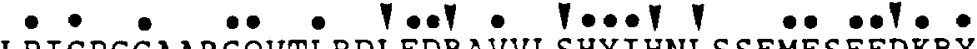

LP ICPGGAARCQVTLRDLEDRAVVLSHYIHNL S SEMF SEFDRRYTHGRGFITK TPVCPNG P GCQVSLRDLFDRAVMVSHYIHNL S SENFNEFDKRYAQGKGF ITM TPVCPNGPGDCQVSLRDLFDRAVMVSHYIHNL S SMFNEFDKRYAQGKGFITM LPICP SGAVNCQVSLRDLFDRAVILSHYIHNLS SEMFNEFDKRYAQGRG P ITK LPVCSGG DCQTPLPELFDRVVMLSHYIHTLYTDMFIEFDKQYVQDREF IAK LPICSAG DCQTSLRELFDRVVILSHYIHTLYTDMFIEEDKQYVQDREFMVK LPICPSGAVNCQVSLRDLFDRAVILSHYIHNLS SEMFNEF DKRYAQGRGPITL VGLNDLLERASELSDKLHSLSTSLTNDLDSHFPPVGRVMMP IGLSDLMERASQRSDKLHSLSTSLTKDLDSHF P PMGRVMMP IGLSDLMERASOR SDKLHSLSTSLTKDLDSHF P PMGRVMMP VPINELFERASQHSDKLHSLSTTLTQELDSHFP P IGRVIMP VPINDLIYRA SQQSDKLHALSTMLTQELGSEAFPIDRVLA

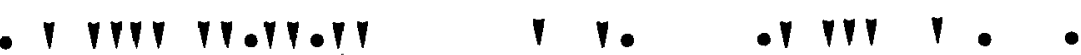
AINSCHT SSLATPEDREQAQQMNQKDFLSLIVS ILR SWNEPLYHLVTEVRGMQ ALN SCHT S L PTPEDKEQAQQTHHEVLMSLILGLLR SWNDPLYHLVTEVRGMK ALNSCHTS SLPTPEDREQAQQTHHEVLMSLILGLLR SWNDPLYHLVTEVRGMK A INSCHTSSLSTPEDKEQAQQIHHEVLLNLILRVLR SWNDPLYHLVTEVRGMQ A INDCPTSSLATPEDKEQAQKVPPEVLLNLILSLVHSWNDPLFQLITGLGGIH VINDCPTSSLATPEDKEQALKVPPEVLLNLILSLVQSS SDPLFQLITGVGGIQ A INSCHTS SLSTPEDKEQAQQ SHHEVLVSLILGVLR SWNDPLYHLVTEVRGMQ RPSMCHTS SLQVPNDKDQALKVPEDPLLSLARSLLLAWSDPLALLSSEASSLA RPSMCHTS SLQTP KDKEQALKV SENELI SLAR SLLLAWNDPLLLLSSEAPTLP RPSMCHTS SLQTPRDKEQALKVSENEL ISLAR SLLLAWNDPLLLLSSEAPTLP RPAMCHTS SLQTPIDKDQALQVSESDLMSLAR SLLQAWSDPLVVLSSSASTLP

$$
\text { CHTSSLQTPTDKEQALQVSESDLLSLARSLLQAWSDPLEVLSSSTNVLP }
$$

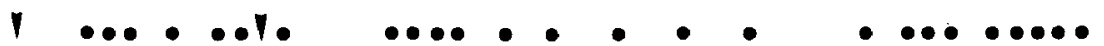

EAPEAILSKAVEIEEQTKRLLEGMELIVSQVHPETRENEIYPVWSGLPSLQMA GAPDAILSRAIEIEEENKRLLEGMEMIEGQVIPGAKETEPYPVWSGLPSLQTK GVPDA ILSRA IEIEEENKRLLEGMEMIFGQVIPGAKETEPYPVWSGLPSLQTR EAPDA ILSRAIEIEEENKRLLEGMERIVGQVHPG I KENEVYSVWSGLP SLQMA EAPDA I I SRAKE IEEQNKRLLEGI EKI I GQAYPEAKGNE IYLVWSQLP SLQGV EAPEY ILSRAKE IEEQNKQLLEGVER I I SQAYPEAKGNG IYFVWSQLP SLQGV EAPDA ILSRA I I IEEQNLRLLEGMERIVGQVN PGVKENEVY SVWSGLP SLQMA H PERNTIDSKTKELQENINSLGRGLEHVFNKMDSTSDNLSSLPFYTNSL GE H PSNGDISSRIRELQDYSKSLGDGLDIMVNRMGPSSQYISSIPERGGDL GN H PSNGDISSRIRELQDYSKSLGDGLDIMVNKMGPSSQYISSIPFKGGDL GN H PAQSTIFNKIQEMQQYSKSLRDGLDVLSSRMGSPAQAITSLPYRGGTNLGH Y SAQSTLSKTIQKMQENSKDLRDGLDILSSKMGPAAQTITSLPEIETNEIGQ

1. DEESRLSAYYNLLHCLRRDSHKIDNYLRLLKCRI IHNNNC DEDARHSAFYNLLHCLRRDSSRIDTYLKLLNCRI IYNNNC DEDTRLFAFYNLLHCLRRDSHKIDNYLRLLKCRI IYNSNC DEESRDLAFYNNIRCLRRDSHRVDHYLKELRCQI VHKNNC DEESRILSLRNTIRCLRRDSHKVDNFLRVLRCQI AHQNNC DEDTRLFAFYNLLHCLRRDSHKIDNYLRLLKCRI IYDSNC DRTSRLVNFHFLLSCFRRDSHRIDSFLKVLRCRAKK RPEMC DRT SRLINFHFLMSCFRRD SHR IDSFLKVLRCRATKMRPETC DKTSRLINFHFLMSCFRRDSHKIDSELKVLRCRATRMRPEAC DRITKLINFNFLLSCLRRDSHRIDSFLKVLRCRAAKMQPEMC DRITK L LSCFRRDSHRIDSFLRVLRCRAANMQPQVC

FIG. 6. Amino acid sequences comparison of seven mammalian and five fish mature PRLs. Gaps were made to maximize homology. Arrows indicates identical or nearly identical (one mismatch allowed) among all PRLs. Identical residues among all mammalian PRLs are represented by dots and those among all fish PRLs are represented by stars.

curred mainly by regional redundant duplication. The diploid content of several tilapia species is 44 chromosomes (Kornfield et al., 1979), close to the average for teleost fish (48). Thus, it is logical to believe that the two tilapia PRLs arose by tandem duplication of a single gene, followed by divergent evolution. It is noteworthy that only one growth hormone has been found so far in two species of tilapia, at the protein level for $O$. mossambicus (Farmer et al., 1976; Specker et al., 1985b) and at the cDNA level for O. niloticus (Rentier-Delrue et al., 1989, accompanying 


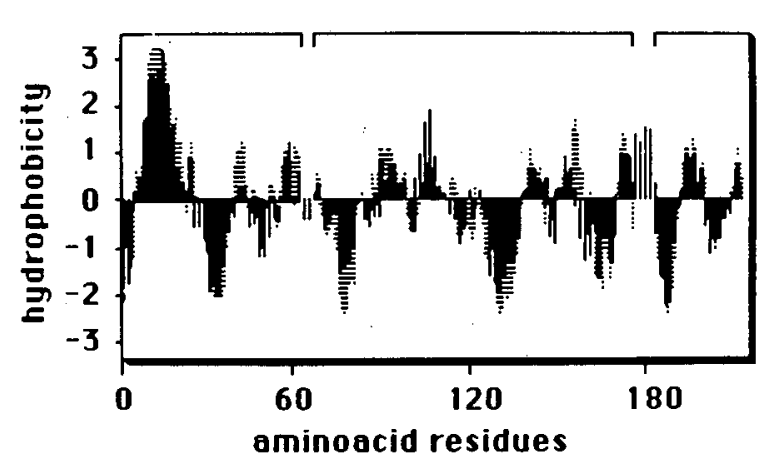

FIG. 7. Superimposed hydropathy profiles of tiPRL-I and tiPRL-II. tiPRL-II profile has been interrupted at two locations, corresponding to the deleted amino acids and indicated by gaps in the upper frame, to match the corresponding profile of tiPRL-I. Vertical lines and horizontal lines represent profiles of tiPRL-I and tiPRL-II, respectively. Black areas represent overlapping profiles.

paper). In the eel family, two growth hormones and one PRL have been isolated from the species Anguilla japonica (Kishida et al., 1987).

Comparison of both tilapia PRLs with PRLs of trout (Salmo gairdneri) (Mercier et al., 1989), chum salmon (Oncorhynchus keta) (Yasuda et al., 1986), and carp (Cyprinus carpio) (Yasuda et al., 1987) reveals that tiPLRI is more similar to all fish PRL than tiPRL-II. tiPRL-I is $68 \%$ similar to trout or chum salmon PRL (which differ by only 1 amino acid) and $64 \%$ similar to carp PRL, while tiPRL-II is only $53 \%$ and $50 \%$ similar to trout or chum salmon and carp PRL, respectively. Seven mammalian and five teleost PRLs were compared (Fig. 6). The most striking structural difference between fish and mammalian PRL is the absence, in the fish hormones, of the small disulfide loop at the amino terminus, as occurs in all $\mathrm{GH}$ molecules. However, it has been shown that this $\mathrm{Cys}_{4-11} \mathrm{di}-$ sulfide loop in PRL is not required to maintain the biological activity of PRL in vertebrates (Doneen et al., 1979). In all PRLs, four regions of highly conserved amino acids are found (18-32, 58-72, 80-98, and 176-193 in this alignment). The divergence between mammalian and teleost PRLs in the nonconserved regions is obvious and probably reflects the physiological differences that exist between mammals and teleost fish. When fish PRLs are compared among themselves, 84 amino acids out of 188 are identical. However, when tiPRL-II is excluded from the comparison, the number of identical residues climbs to 103. This tends to put tiPRL-II aside from the other PRLs and leads us to believe that tiPRL-II evolved under less stringent constraints and might have distinct biological properties, except for its osmoregulatory functions, which appear to be maintained. Indeed, tiPRL-I and tiPRL-II act on freshwater osmoregulation in a similar fashion. Both PRLs restore normal plasma ion levels and transepithelial potential (TEP) in hypophysectomized tilapia transferred to freshwater (Specker et al., 1985a; Young et al., 1988). Moreover, neither PRL restores gill $\mathrm{Na}^{+}-\mathrm{K}^{+}$ATPase activity in hypophysectomized tilapia, suggesting that, in freshwater, both hormones may act on epithelial permeability to $\mathrm{Na}^{+}$ (Young et al., 1988). Studies on the neuroendocrine control of tiPRL-I and tiPRL-II production indicate that somatostatin (SRIF) and urotensin II inhibit similarly the in vitro release of both tiPRLs (Rivas et al., 1986). The only difference between tiPRL-I and tiPRL-II in the osmoregulatory aspects studied so far is found in the dose-dependency of the effects on integumental TEP in salamander (Young et al., 1988).

Superimposition of hydropathy profiles of both tilapia PRLs, taking into account the deleted regions of tiPRL-II, reveals that the first missing domain is hydrophilic and the second is very hydrophobic and therefore believed to be located inside the molecule (Fig. 7). If these deletions induce a change in the conformation of the molecule, they have a very weak effect on the osmoregulatory functions of tiPRLs. Growth-promoting activity seems to differ more markedly in the two proteins, since tiPRL-I displays this type of activity in juveniles of the tilapia $O$. mossambicus while tiPRL-II does not (Specker et al., 1985b).

To characterize the tilapia PRLs better, we have expressed tiPRL-I in $E$. coli. The expression system based on the T7 RNA polymerase was used because it offers stringent control and good level of expression (Studier and Moffatt, 1986). Using this system, we constructed a recombinant expression vector containing the cDNA coding for the tiPRL-I. The expression plasmid directed the synthesis of tiPRL-I very efficiently, since the level of expression achieved was approximately $45 \%$ of the total cellular protein. The newly synthesized protein was found as insoluble granules. A similar strategy currently is being used to express the smaller prolactin (tiPRL-II).

\section{ACKNOWLEDGMENTS}

This work was supported by grant C320 from the Région Wallonne, Ministère des Technologies Nouvelles, Belgium. We are grateful to Dr. A. Renard (Eurogentec, Liège, Belgium) for helpful discussions. We also thank Dr. J.C. Philippart (Laboratoire de Démographie des Poissons et de Pisciculture, Université de Liège, Belgium) and the members of the CERER-Pisciculture (Tihange, Belgium) for providing tilapias and for their help in collecting the pituitaries.

\section{REFERENCES}

CHIRGWIN, J.M., PRZYBYLA, A.E., MACDONALD, R.J., and RUTTER, W.J. (1979). Isolation of biologically active ribonucleic acid from sources enriched in ribonuclease. Biochemistry 18, 5294-5299.

CLARKE, W.C. (1973). Sodium-retaining bioassay of prolactin in the intact teleost Tilapia mossambica acclimated to sea water. Gen. Comp. Endocrinol. 21, 498-512.

CLARKE, W.C., and BERN, H.A. (1980). Comparative endocrinology of prolactin. In Hormonal Proteins and Peptides, vol. 8, C.H. Li, Ed. (Academic Press, New York) pp. 105-197. 
DHARMAMBA, M. (1970). Studies of the effects of the hypophysectomy and prolactin on plasma osmolality and plasma sodium in Tilapia mossambica. Gen. Comp. Endocrinol. 14, 256-269.

DHARMAMBA, M., and MAETZ, J. (1972). Effect of hypophysectomy and prolactin on the sodium of Tilapia mossambica in freshwater. Gen. Comp. Endocrinol. 19, 175-183.

DHARMAMBA, M., and MAETZ, J. (1976). Branchial sodium exchange in seawater-adapted Tilapia mossambica: Effects of prolactin and hypophysectomy. J. Endocrinol. 70, 293-299.

DONEEN, B.A., BEWLEY, T.A., and LI, C.H. (1979). Studies on prolactin, selective reduction of disulfide bonds of the bovine hormone. Biochemistry 18, 4851-4860.

FARMER, S.W., PAPKOFF, H., HAYASHIDA, T., BEWLEY, T.A., BERN, H.A., and LI, C.H. (1976). Purification and properties of teleost growth hormone. Gen. Comp. Endocrinol. 30, 91-100.

FOSKETT, J.K., MACHEN, T.E., and BERN, H.A. (1982). Chloride secretion and conductance of teleost opercular membrane effects of prolactin. Am. J. Physiol. 242, Regul. Integr. Comp. Physiol. 11, R380-R389.

GRUNSTEIN, M., and HOGNESS, D.S. (1975). Colony hybridization: A method for the isolation of cloned DNAs that contain a specific gene. Proc. Natl. Acad. Sci. USA 72, 3961-3965.

GUBLER, U., and HOFFMAN, B.J. (1983). A simple and very efficient method for generating cDNA libraries. Gene 25, 263269.

HIRANO, T. (1986). The spectrum of prolactin action in teleosts. In Comparative Endocrinology: Developments and Directions, C.L. Ralph, Ed. (Alan R. Liss Inc., New York) pp. 53-74.

KAWAUCHI, M. (1983). Chemistry of proopiocortin-related peptides in salmon pituitary. Arch. Biochem. Biophys. 227, 343-350.

KISHIDA, M., HIRANO, T., KUBOTA, J., HASEGAWA, S., KAWAUCHI, H., YAMAGUCHI, K., and SHIRAHATA, K. (1987). Isolation of two forms of growth hormone secreted from eel pituitaries in vitro. Gen. Comp. Endocrinol. 65, 478-488.

KORNFIELD, I.L., RITTE, U., RICHTER, C., and WARHMAN, J. (1979). Biochemical and cytological differentiation among Cichlid fishes of the sea of Galilee. Evolution 33, 1-14.

KYTE, J., and DOOLITTLE, R.F. (1982). A simple method for displaying the hydropathic character of a protein. J. Mol. Biol. 157, 105-132.

LAEMMLI, U.K. (1970). Cleavage of structural proteins during the assembly of the head of bacteriophage T4. Nature 227, 680-685.

LORETZ, C.A., and BERN, H.A. (1982). Prolactin and osmoregulation in vertebrates. Neuroendocrinology 35, 292-304.

MANDEL, M., and HIGA, A. (1970). Calcium dependent bacteriophage DNA infection. J. Mol. Biol. 53, 159-162.

MERCIER, L., RENTIER-DELRUE, F., SWENNEN, D., LION, M., LE GOFF, P., PRUNET, P., and MARTIAL, J.A. (1989). Rainbow trout prolactin cDNA cloning in $E$. coli. DNA 8, $119-125$

NARANG, S.A., HSIUNG, H.M., and BROUSSEAU, R. (1979). Improved phosphotriester methods for the synthesis of gene fragments. Methods Enzymol. 68, 90-98.

OHNO, S., WOLF, U., and ATKIN, N.B, (1968). Evolution from fish to mammals by gene duplication. Hereditas 59, 169187.

PRUNET, P., and BORNANCIN, M. (1989). Physiology of sa- linity tolerance in tilapia: An update and basic applied aspect. Aquat. Liv. Sec. (in press).

RENTIER-DELRUE, F., SWENNEN, D., PHILIPPART, J.C., L'HOIR, C., LION, M., BENRUBI, O., and MARTIAL, J.A. (1989). Tilapia growth hormone: Molecular cloning of cDNA and expression in Escherichia coli. DNA 8, 271-278.

RIVAS, R.J., NISHIOKA, R.S., and BERN, H.A. (1986). In vitro effects of somatostatin and urotensin II on prolactin and growth hormone secretion in tilapia Oreochromis mossambicus. Gen. Comp. Endocrinol. 63, 245-251.

ROSENBERG, A.H., LADE, B.N., CHUI, D.S., LIN, S.W., DUNN, J.J., and STUDIER, F.W. (1987). Vectors for selective expression of cloned DNAs by T7 RNA polymerase. Gene 56, 125-135.

SANGER, F., NICKLEN, S., and COULSON, A.R. (1977). DNA sequencing with chain-terminating inhibitors. Proc. Natl. Acad. Sci. USA 74, 5463-5467.

SONG, S., TRINH, K.Y., HEW, C.L., HWANG, S.J., BELKHODE, S., and IDLER, D.R. (1988). Molecular cloning and expression of salmon prolactin cDNA. Eur. J. Biochem. 172, 279-285.

SPECKER, J.L., KING, D.S., NISHIOKA, R.S., SHIRAHATA, K., YAMAGUCHI, K., and BERN, H.A. (1985a). Isolation and partial characterization of a pair of prolactins release in vitro by the pituitary of a cichlid fish, Oreochromis mossambicus. Proc. Natl. Acad. Sci. USA 82, 7490-7494.

SPECKER, J.L., KING, D.S., RIVAS, R.J., YOUNG, B.K. (1985b). Partial characterization of two prolactins from a cichlid fish. In Prolactin. Basic and Clinical Correlates, Vol. 1, R.M. MacLeod, M.O. Thorner, and U. Scapagnigni, Eds. (Fidia Research 'Series, Liviana Press, Padova, Italy) pp. 427436.

STUDIER, F.W., and MOFFATT, B.A. (1986). Use of bacteriophage T7 RNA polymerase to direct selective high-level expression of cloned genes. J. Mol. Biol. 186, 113-130.

TOBWIN, H., STAEHELIN, T., and GORDON, J. (1979). Electrophoretic transfer of proteins from polyacrylamide gels to nitrocellulose sheets: Procedure and some applications. Proc. Natl. Acad. Sci. USA 76, 4350-4354.

ULLRICH, A., SHINE, J., CHIRGWIN, J., PICTET, R., TISCHER, E., RUTTER, W.J., and GOODMAN, H.M. (1977). Rat insulin genes: Construction of plasmids containing the coding sequences. Science 196, 1313-1319.

VIERA, J., and MESSING, J. (1982). The pUC plasmids, an $\mathrm{m} 13 \mathrm{mp} 7$-derived system for insertion mutagenesis and sequencing with synthetic universal primers. Gene 19, 259-268.

YAMAGUSHI, K., SPECKER, J.L., KING, D.S., YOKOO, Y., NISHIOKA, R.S., HIRANO, T., and BERN, H.A. (1988). Complete amino acid sequence of a pair of fish (tilapia) prolactins $\mathrm{PRR}_{17}$ and $\mathrm{TPRL}_{188}$. J. Biol. Chem. 263, 9113-9121.

YANISCH-PERRON, C., VIERA, J., and MESSING, J. (1985). Improved M13 phage cloning vectors and host strains: Nucleotide sequences of the M13 mp18 and pUC19 vectors. Gene 33, 103-119.

YASUDA, A., ITOH, H., and KAWAUCHI, H. (1986). Primary structure of chum salmon prolactins: Occurrence of highly conserved regions. Arch. Biochem. Biophys. 244, 528541.

YASUDA, A., MIYAZIMA, K.I., KAWAUCHI, H., PETER, R.E., LIN, H.R., YAMAGUCHI, K., and SANO, H. (1987). Primary structure of common carp prolactins. Gen. Comp. Endocrinol. 66, 280-290. 
YOUNG, P.S., MCCORMICK, S.D., DEMAREST, J.R., LIN, R.J., NISHIOKA, R.S., and BERN, H.A. (1988). Effects of salinity, hypophysectomy and prolactin on whole-animal transepithelial potential in the tilapia Oreochromis mossambicus. Gen. Comp. Endocrinol. 71, 389-397.

Address reprint requests to:

Dr. J.A. Martial

Laboratoire Central de Génie Génétique Université de Liège B6, Sart Tilman

4000 Liège, Belgium

Received for publication January 12, 1989. 